УДК 661.666: 66.096.5

С.С. Федоров /д.т.н./,

Національна металургійна академія

України, м. Дніпро, Україна

А.В. Сибір /к.т.н./,

TOВ «ТМЕС», м. Дніпро, Україна

М.В. Губинський /д.т.н./,

С.М. Губинський /магістр/,

С.М. Форись /к.т.н./,

Національна металургійна академія

О.Г. Гогоці /магістр/,

України, м. Дніпро, Україна

С.В. Коваль /магістр/

\title{
ДОСЛІДЖЕННЯ РЕЖИМІВ РОБОТИ ПІЛОТНОЇ ЕЛЕКТРОТЕРМІЧНОЇ ПЕЧІ КИПЛЯЧОГО ШАРУ ПРОДУКТИВНІСТЮ 10 КГ/ГОД
}

S.S. Fedorov /Dr. Sci. (Tech.)/,

A.V. Sybir /Cand. Sci. (Tech.)/, M.V. Hubynskyi /Dr. Sci. (Tech.)/, S.M. Hubynskyi /M.Sc./,

S.M. Foris /Cand. Sci. (Tech.)/, O.G. Gogotsi /M.Sc./,

S.V. Koval /M.Sc./
National Metallurgical Academy of

Ukraine, Dnipro, Ukraine

TMEC Ltd., Dnipro, Ukraine

National Metallurgical Academy of Ukraine, Dnipro, Ukraine

\section{STUDY OF THE OPERATING MODES \\ FOR THE ELECTRO-THERMAL FLUIDIZED BED FURNACE OF 10 KG/H PRODUCTIVITY}

Мета. Метою дослідження режимів лабораторної електротермічної печі киплячого шару продуктивністю 10 кг/год було отримання нових науково-практичних даних про вольт-амперні характеристики подібних агрегатів для подальшого вибору відповідних електричних джерел живлення.

Методика. Дослідження роботи печі виконувалось шляхом математичного моделювання їі теплового балансу та електричного опору у відповідних режимах. Для побудови вольт-амперних характеристик були використані залежності для електричної потужності та питомого електричного опору шару, а також рівняння загальної, корисної потужності і потужності холостого ходу за різних значень робочої температури і продуктивності.

Результати. Побудовані $і$ досліджені воль-амперні характеристики печі киплячого шару продуктивністю 10 кг/год, які включають: характеристики електротермічного киплячого шару для певних значень температури в діапазоні від 0 до $2700^{\circ} \mathrm{C}$; характеристики електротермічного киплячого шару для продуктивності печі $G=0$ - 10 кг/год; криві шільності струму на поверхні центрального електроду, на поверхні футеровки і середньої за радіусом печі і(I); криві постійної потужності $N=$ const в діапазоні $5-40 \kappa B m$. На основі аналізу результатів визначена область сталої роботи електротермічної печі, яка виключає ймовірність короткого замикання. Розроблені режими розігріву, зміни температури і продуктивності, а також алгоритми забезпечення заданих продуктивності й температури.

Наукова новизна. Вперше науково обгрунтовано вибір режимів управління електричною потужністю електротермічної печі киплячого шару на основі ї̈ вольт-амперних характеристик та визначено область сталої роботи.

() Федоров С.С., Сибір А.В., Губинський М.В., Губинський С.М., Форись С.М., Гогоці, О.Г. Коваль С.В., 2019 г. 
Практична значущість. За результатами досліджень визначені вимоги та відповідно розроблене технічне завдання на виготовлення електричного джерела живлення лабораторної електротермічної печі киплячого шару продуктивністю 10 кг/год для умов ТОВ «Центр Матеріалознавства» (Київ, Украӥна).

Ключові слова: електротермічна піч, киплячий шар, рафінування графіту, режими роботи.

\section{DOI: $10.34185 / 0543-5749.2019-3-4-48-55$}

Вступ. Завдяки своїм унікальним властивостям графіт став невід'ємною частиною виробів, які використовуються в енергетиці, машинобудуванні та металургії. Сфера застосування даного матеріалу постійно розширюється, визначаючи тим самим його споживчий попит. За спостереженнями експертів, стала динаміка ринку графіту знаходиться в тісному взаємозв'язку із загальним станом глобальної економіки: тільки 3 2012 по 2016 рр. ринок виріс на 9 \% [1 - 2].

Промислова технологія електротермічного киплячого шару (EFB), створена інженерами Thermal and Material Engineering Center, забезпечує поточне рафінування вуглецевої сировини до рівня 99,95-99,995 \% [3 - 5]. Отримані матеріали мають покращені фізичні та хімічні властивості (зокрема тепло- та електропровідність, кристалічну структуру, густину), що робить їх затребуваними у виробництві літієвих акумуляторів, сталеплавильній та алюмінієвій промисловості, виробництві захисних фарб, покриттів, вогнестійкої теплової ізоляції тощо.

Аналіз літературних даних та постановка проблеми. Реалізація технології ЕFВ в електротермічних печах киплячого шару (ЕТПКШ) забезпечується розмірами робочого простору, 3 одного боку, та відповідними електротермічними режимами, з іншого. Як показує досвід численних математичних та фізичних моделей EFB, вирішення останньої задачі важливе 3 точки зору вибору електричного джерела живлення та розробки алгоритму управління процесу [6].

Ключовим параметром роботи високотемпературних ЕТПКШ, який у підсумку визначає теплову потужність і робочу температуру процесу, $є$ питомий електричний опір псевдозрідженого матеріалу. Сучасний науковий доробок багатьох вчених [7-9] вказує на складність та неоднозначність явища електричної провідності киплячого шару, його вплив на роботу печей та необхідність системного аналізу показників роботи цих агрегатів на його основі.

На цьому тлі, основними проблемами подальшого розвитку технології отримання батарейного графіту на базі ЕТПКШ в Україні та світі в цілому є відсутність достатнього досвіду експлуатації та науково обгрунтованих методів ро- зрахунку та конструювання енергоефективних агрегатів. Отже, розвиток теоретичних основ теплової роботи та розробки ефективних конструкцій ЕТПКШ, а також технологічних комплексів на їх основі $\epsilon$ актуальним.

В цьому зв'язку актуальним є дослідження електротермічних режимів ЕТПКШ для визначення меж їх сталої роботи та уточнення вимог щодо джерел живлення.

Мета і завдання досліджень. Метою дослідження режимів лабораторної електротермічної печі киплячого шару продуктивністю 10 кг/год було отримання нових науково-практичних даних про вольт-амперні характеристики подібних агрегатів для подальшого вибору відповідних електричних джерел живлення.

Матеріали та методи дослідження. Об'єктом дослідження виступала лабораторна електротермічна піч, призначена для обробки графіту з розміром фракцій від 100 мкм (рис. 1).

Розрахункова продуктивність установки 0 10 кг/год; максимальна температура обробки $2000-2500{ }^{\circ} \mathrm{C}$. Основні конструктивні розміри: внутрішній діаметр робочого простору - 105 мм; діаметр електроду - 60 мм; висота активної зони - 350 мм; висота ділянки під електродом 200 мм; висота надшарової зони - 500 мм; діаметр активної зони нагріву - 105 мм; зовнішній діаметр графітової футеровки - 305 мм; зовнішній діаметр теплової ізоляції - 705 мм.

Дослідження роботи печі виконувалось шляхом математичного моделювання іiі теплового балансу та електричного опору у відповідних режимах. Для побудови вольт-амперних характеристик були використані авторські залежності для електричної потужності $\mathrm{N}=\mathrm{U} \cdot \mathrm{I}=\mathrm{I}^{2} \cdot \mathrm{R}$ і питомого електричного опору (ПЕО) шару, а також математична модель печі для розрахунку загальної, корисної потужності і потужності холостого ходу за різних значень робочої температури і продуктивності [7 - 8].

Результати дослідження. За результатами моделювання, графічна залежність ПЕО киплячого шару від потужності тепловиділень в одиниці об'єму та температури процесу (рис. 2) вказує на її надскладний та неоднозначний характер, що є проблемою в управлінні електро- 
термічними режимами печі. Класичне уявлення про енергетичну характеристику ЕТПКШ як функцію потужності від продуктивності N (G) € малоінформативним, оскільки основний інтерес в регулюванні представляє взаємозв'язок струму і напруги. Для пї дослідження були отримані та вивчені вольт-ампері характеристики (BAX) печі.

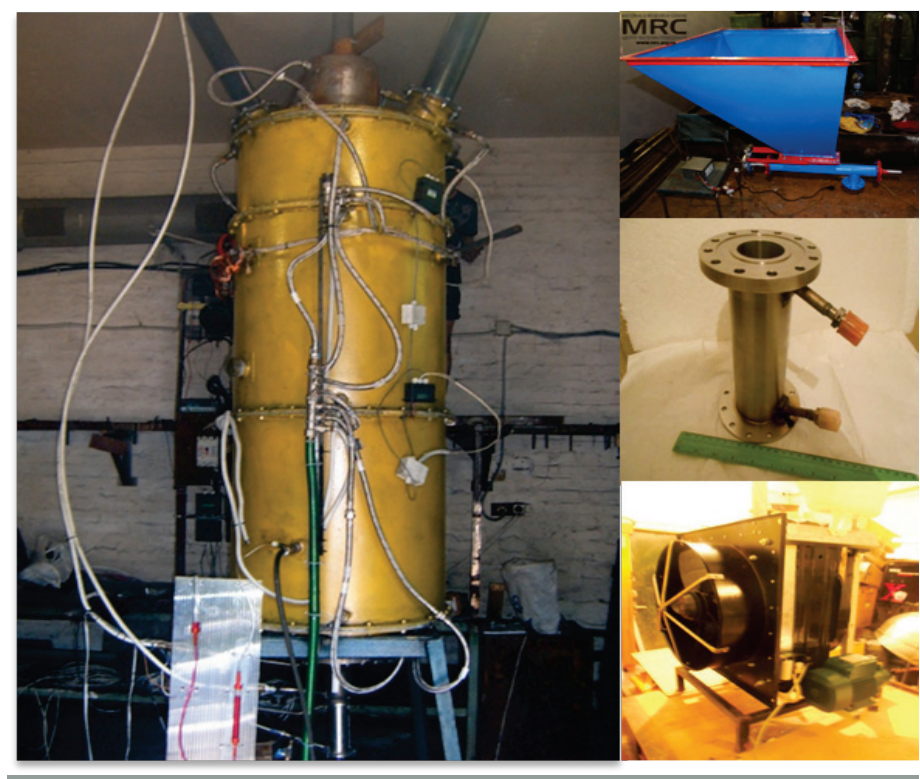

Рис. 1. Зовнішній вигляд пілотної ЕТПКШ продуктивністю 10 кг/год (Виробник MRC)

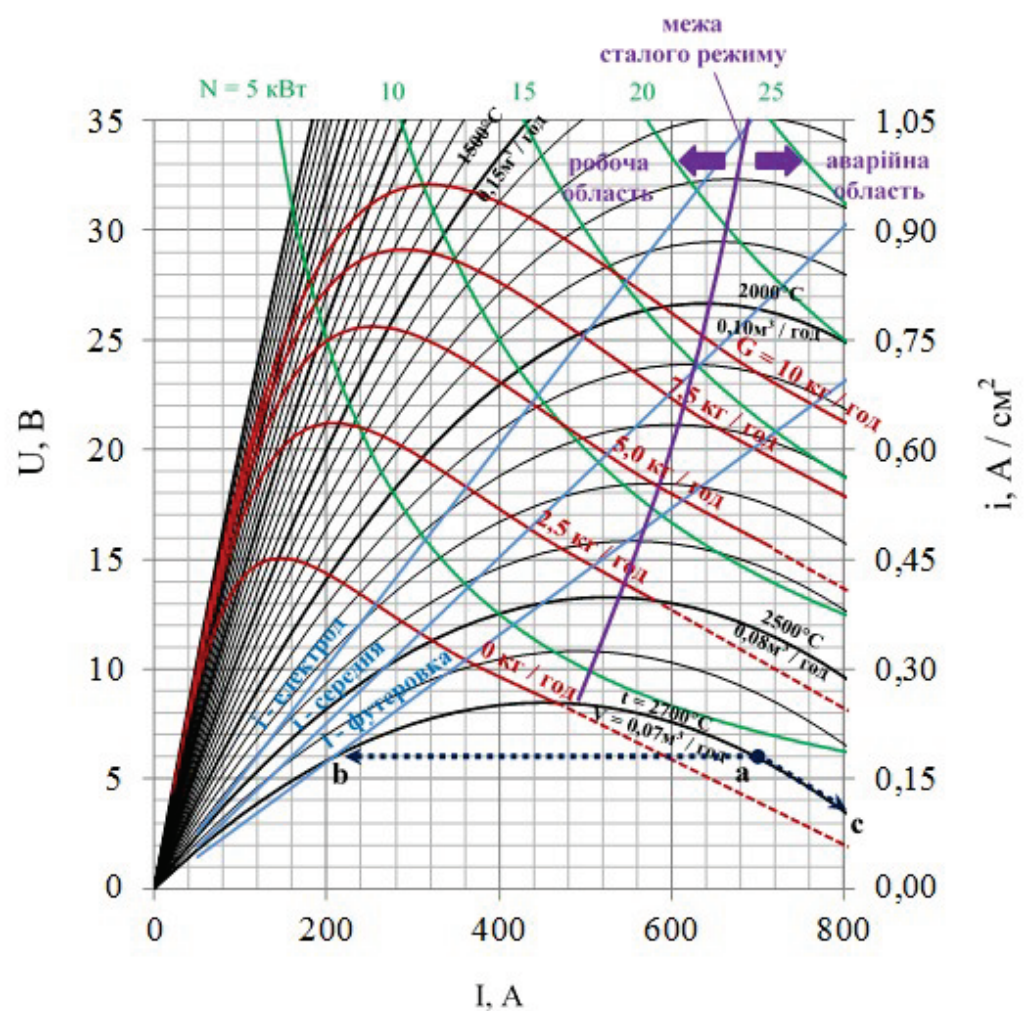

Рис. 2. Вольт-амперна характеристика електротермічної печі 10 кг/г

ВАХ-ки печі включають в себе 4-ри сімейства кривих:

1) ВАХ-ки електротермічного киплячого шару для певних значень температури в діапазоні від 0 до $2700{ }^{\circ} \mathrm{C}$, побудовані 3 кроком $100{ }^{\circ} \mathrm{C}$. Їм відповідають лінії постійної темпера- 
тури (чорні криві). Зазначене сімейство кривих отримано на основі математичної моделі ПЕО. Кожному значенню температури відповідає своя витрата азоту, приведена до нормальних умов на межі стійкості щільного шару $(\mathrm{W}=1)$;

2) ВАХ-ки електротермічного киплячого шару для певної продуктивності печі $\mathrm{G}=0$ 10 кг/год, побудовані 3 кроком 2,5 кг/год (червоні криві). Це так звані лінії постійної витрати матеріалу. Даний тип кривих отримано шляхом сполученого рішення рівняння теплового балансу печі певної конструкції з урахуванням можливих електротермічного i гідродинамічного режимів, а також математичної моделі ПЕО. Для їх побудові в якості вихідних даних задавалися продуктивність печі та температура процесу, після чого знаходились напруга і струм;

3) Криві щільності струму на поверхні центрального електроду, на поверхні футеровки і середньої за радіусом печі і(I) зі шкалою значень на допоміжній осі. Даний тип кривих носить інформативний характер для оцінки умов роботи, перш за все, центрального електроду;

4) Криві постійної потужності $\mathrm{N}=$ const в діапазоні 5 - 40 кВт 3 кроком 5 кВт, які спільно 3 лініями 2-го типу $(\mathrm{G}=\mathrm{const})$ неявно представляють енергетичну характеристику агрегату.

Як випливає 3 рис. 3 питання управління роботою печі вимагає системного аналізу. Кожна точка на діаграмі відповідає певному стану печі, що характеризується продуктивністю, температурою, струмом, напругою, потужністю i щільністю струму. Крім цього, тут же неявно заданий ПЕО шару, значення якого пропорційно тангенсу кута нахилу променю, що проходить через початок координат і робочу точку.

Характер кривих 3-го і 4-го типу щодо потужності і щільності струму однозначний, оскільки функціональні зв'язки визначаються простими математичними залежностями, які не потребують окремих пояснень.

BAX-ки киплячого шару (криві 1-го типу) мають виражений максимум, що обумовлено взаємним впливом температури і питомих тепловиділень в одиниці об'єму на величину його ПЕО. Як видно з рис. 3, заданій напрузі джерела можуть відповідати дві величини робочого струму. Отже, існує свого роду невизначена область, в якій можуть проявлятися явища помпажу.

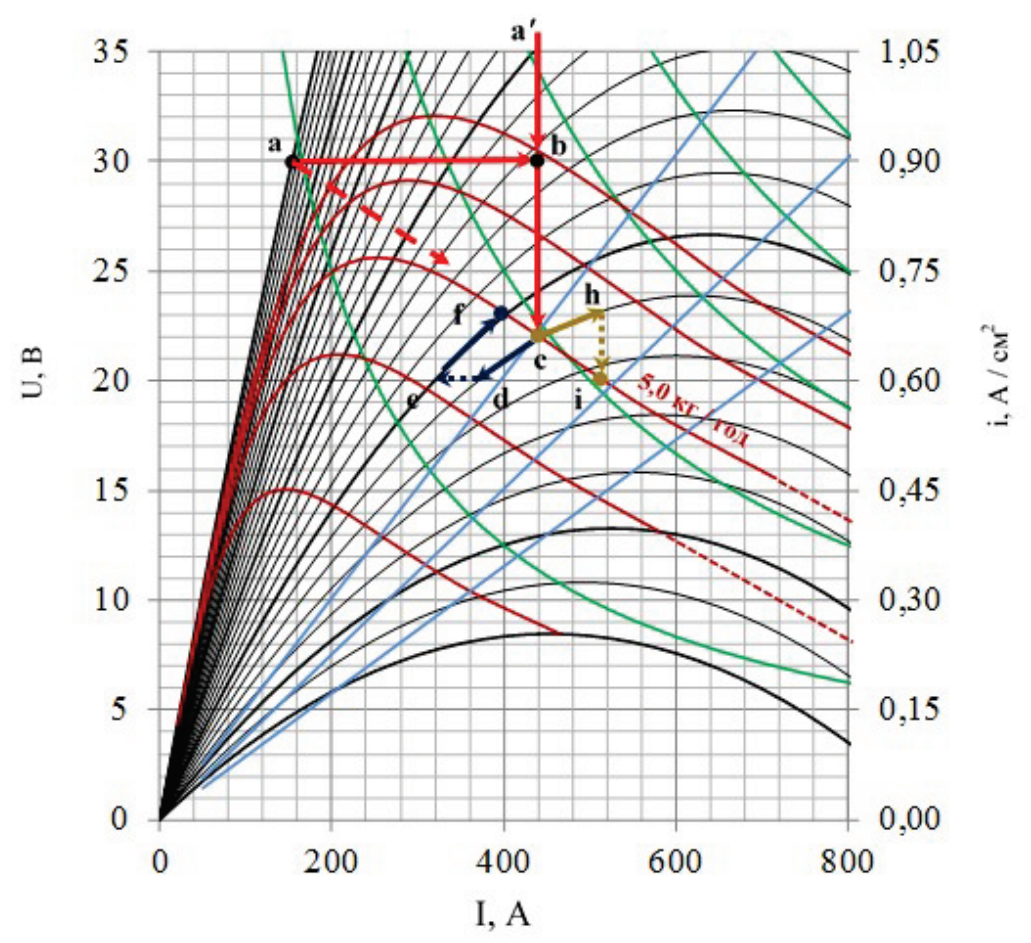

Рис. 3. Спосіб управління електротермічним режимом ЕТПКШ

Обговорення результатів. Аналіз ізотерм показує, що за експлуатації печі на низхідній гілці, коли щільність струму відповідає більшому значенню, система буде несталою. Наприклад, такому стану відповідає положення точки «а» на рис. 3. Будь-який незначний, локальний у часі збурюючий фактор пов'язаний зі зміною щільності киплячого шару виведе систему з рівноваги. Це призведе до раптового зменшення величини робочого струму в напрямку «аb» i падіння потужності або ж, навпаки, короткого замикання ланцюга, в напрямку «ас». Слід за- 
уважити, що режим короткого замикання електротермічного киплячого шару не описується математична моделлю його ПЕО. Тому напрямок «ас» в даному випадку показано умовно. На висхідній гілки ізотерми шар перебуває в режимі далекому від короткого замикання ланцюга. Проте спонтанний перехід з точки «b» в стан «а» також не може бути виключений. Частота таких переходів може відповідати пульсаційній гідродинамічній характеристиці шару 2-7 Гц. Для виключення подібних коливань і запобігання різкого збільшення потужності, дана особливість повинна в обов'язковому порядку враховуватися під час проектування джерела живлення.

3 наведених міркувань запропонована так звана межа стійкості (рис. 3), яка проходить через екстремуми ізотерм та розділяє діаграму на робочу і аварійну області.

Схожі властивості мають також криві 2-го типу для постійної продуктивності. Низхідний характер за температур понад $1500{ }^{\circ} \mathrm{C}$, як і в разі ізотерм, обумовлений зниженням ПЕО киплячого шару. Як випливає 3 діаграми для частинок заданого розміру, кожній продуктивності відповідає своя гранична температура, яка може бути досягнута в процесі експлуатації. Ця температуpa знаходиться в точці дотику лінії U (I, $\mathrm{G}=$ const) до кривої $\mathrm{U}(\mathrm{I}, \mathrm{t}=\mathrm{const})$. Наприклад, для продуктивності $\mathrm{G}=2,5$ кг/год розрахункова гранична температура процесу знаходиться в діапазоні $2500-2600{ }^{\circ} \mathrm{C}$. Оскільки дана точка розташовується в правій частині діаграми за межами позначеної межі стійкості, то дійсна температура обробки матеріалу, яка може бути досягнута, буде дещо меншою. Інтервал робочих температур водночас буде визначатися перетином лінії $U$ (I, G = const) 3 безліччю кривих $\mathrm{U}(\mathrm{I}, \mathrm{t}=\mathrm{const})$ в робочій області діаграми. Так для продуктивності $\mathrm{G}=2,5$ кг/год реальний діапазон температур буде відповідати умові $\mathrm{t} \leq 2400{ }^{\circ} \mathrm{C}$.

У визначенні способу управління електротермічними режимами ЕТПКШ представляють інтерес процеси пов'язані з розігрівом печі, регулюванням температури і продуктивності. Для наочності даний аналіз виконаний щодо режиму експлуатації агрегату 3 продуктивністю 5,0 кг/год (рис. 3). Отримані висновки водночас можуть бути екстрапольовані як інші витрати матеріалу, так і на інші конструкції ЕТПКШ.

Режими розігріву ЕТПКШ. Наявність максимуму для ліній $\mathrm{G}=$ const в інтервалі температур до $1500{ }^{\circ} \mathrm{C}$ говорить про те, що для менших значень напруги розігрів печі буде проходити до деякої температури $\mathrm{t}<1500{ }^{\circ} \mathrm{C}$. Наприклад, мак- симуму кривої $\mathrm{G}=5$ кг/год відповідає напруга $\mathrm{U}=25,6 \mathrm{~B}$. Під час розігріву в режимі $\mathrm{U}<25,6 \mathrm{~B}$ настане рівноважний стан системи, що задовольняє умовам теплового балансу і певного електричного опору. Піч водночас залишається «холодною». Для досягнення температур $2000-$ $2500{ }^{\circ} \mathrm{C}$ необхідна реалізація особливого алгоритму управління печі за $\mathrm{U} \geq 25,6 \mathrm{~B}$.

Швидкість розігріву печі буде визначатися величиною потужності, що підводиться. Аналогічно для будь-якого теплового агрегату динаміка розігріву повинна в обов'язковому порядку враховувати процеси видалення вологи 3 футерування і теплової ізоляції, а також можливі термічні напруги в елементах конструкції.

3 рис. 3 видно, що вихід на заданий режим, визначений точкою «с» може бути реалізований трьома способами.

Перший полягає в початковій стадії розігріву за деякої постійної напруги до розрахункового струму печі (процес «ab») з подальшою стадією за постійного струму (процес «bc»). Даний режим передбачає збільшення потужності до точки «b» і потім іï зниження.

Альтернативою даному способу є розігрів за постійного розрахункового струму $з$ поступовим зменшенням напруги джерела (процес «а'bc»). Очевидним недоліком є велика початкова потужність, що підвищує вимоги до джерела живлення і створює небезпеку термічних напружень через нерівномірне прогрівання печі.

Третій режим в напрямку «ас» поєднує в собі ознаки двох попередніх і $є$ найбільш «м'яким» в плані нагріву, оскільки передбачає реалізацію процесу з поступовим нарощуванням потужності за зниження напруги й збільшення струму. Недоліком є тривалість періоду розігріву, яка згідно з експертною оцінкою становитиме близько 20-24 годин. Крім того, на певній стадії перетину кривих $\mathrm{G}=$ const $\mathrm{i}$ «ас» процес може зупиниться за значно низької температурі, що потребує ускладнення алгоритму управління. Незважаючи на зазначені проблеми даний режим, вочевидь, є найбільш надійним з точки зору вимог до джерела та рівномірності прогрівання печі.

Зміна температурного режиму ЕТПКШ. В управлінні температурним режимом мають місце дві окремі задачі: зниження і збільшення температури. Нижче виконаний їх аналіз щодо базової робочої точки «с» (рис. 3 ).

Варіант переходу системи 3 точки «с» 3 температурою $t_{c}$ в точку «f» 3 більш низькою температурою $t_{f}$ передбачає на початковому етапі зниження напруги джерела живлення. Водночас, 
оскільки система має значну теплову інерційність, режим шару відразу ж перейде в деякий стан «d». Отже, знизиться струм і відповідно потужність печі. В результаті падіння потужності піч опиняється у нестаціонарному режимі поступового охолодження в напрямку «de». По досягненню заданої температури шару $\mathrm{t}_{\mathrm{f}}$ система управління плавно нарощує напругу на електродах для переведення печі в рівноважну робочу точку «f». Водночас переміщення «еf» аналогічно «сd» здійснюється уздовж ізотерми.

Щоб перейти 3 точки «с» в зону більш високих температур $\mathrm{t}_{\mathrm{i}}$, підвищується напруга джерела, $\mathrm{i}$ система уздовж ізотерми $\mathrm{t}_{\mathrm{c}}=$ const переходить в стан «h». Після цього триває розігрів печі, наприклад, за постійного струму до рівноважного стану в точці «і».

Наведений теоретичний аналіз вказує на існування гістерезису електротермічного шару за зміни напруги джерела. Наявність даного явища підтверджується експериментами.

Описаний спосіб регулювання температури, під час автоматизації може бути модифікований на основі його багатоступінчастої реалізації 3 послідовним наближенням до заданої розрахунковій точки.

Зміна продуктивності печі. Необхідність управління продуктивністю ЕТПКШ може бути обумовлена збільшенням потужності після виходу на задану температуру в режимі холостого ходу, змінами обсягу виробництва, а також аварійними ситуаціями. За таких умов управління також здійснюється аналогічно способу регулювання температури.

Для збільшення продуктивності печі поступово підвищується напруга джерела, водночас система змінює свій стан в напрямку «сh» уздовж ізотерми. Для зменшення продуктивності процес виконується в зворотному напрямку.

Слід зазначити, що в цих процесах буде досить складно синхронізувати зміну подачі матеріалу і потужності печі для витримки заданої температури. Тому процес управління в даному випадку повинен включати алгоритм коригування температурного режиму.

Забезпечення сталого режиму ЕТПКШ. Киплячий шар по своїй фізичній природі є несталим в гідродинамічному та електричному плані. Складність ВАX і динамічна зміна опору шару вимагає постійного контролю і управління. У зв'язку з цим, для підтримки роботи ЕТПКШ в заданому статичному стані АСУ ТП повинна використовувати алгоритм аналогічний регулюванню температури. Водночас джерелом сигналу є датчик температури.
Вимоги до системи контролю завантаження печі. Задача регулювання теплових режимів безпосередньо пов'язана зі ступенем завантаження робочого простору. Даний параметр $\epsilon$ ключовим разом із іншими оскільки від нього залежить опір шару, потужність печі та середній час перебування матеріалу в шарі. Через високі температури реалізація візуального та автоматичного контролю рівня завантаження активної зони термообробки являє технічну складність. Електричний опір у змінних режимах роботи не може виступати в якості керуючого параметру.

Оскільки гідравлічний опір киплячого шару $\epsilon$ непрямою характеристикою його висоти, то для ЕТПКШ продуктивністю 10 кг/год був запропонований спосіб контролю ступеня завантаження робочого простору на основі гідравлічних випробувань «холодної» печі.

За результатами досліджень визначені вимоги та відповідно розроблене технічне завдання на виготовлення електричного джерела живлення лабораторної ЕТПКШ продуктивністю 10 кг/год для умов ТОВ «Центр Матеріалознавства» (Київ, Україна).

Висновки. Вперше науково обгрунтовано вибір режимів управління електричною потужністю ЕТПКШ на основі системи кривих, що включають: вольт-амперні характеристики псевдозрідженого шару при температурах до $3000^{\circ} \mathrm{C}$; вольт-амперні характеристики печі для заданої продуктивності; криві щільності струму на поверхні електродів та середньої за радіусом печі і(I); залежності постійної потужності $\mathrm{N}=$ const. На основі аналізу ВАХ визначається область сталої роботи печі.

Шляхом математичного моделювання теплообміну ЕТПКШ і питомого електричного опору шару побудовані і досліджені ВАХ-ки печі, які включають: ВАХ-ки електротермічного киплячого шару для певних значень температури в діапазоні від 0 до $2700{ }^{\circ} \mathrm{C}$; ВАХ-ки електротермічного киплячого шару для продуктивності печі $\mathrm{G}=0$ - 10 кг/год; криві щільності струму на поверхні центрального електроду, на поверхні футеровки і середньої за радіусом печі i(I); криві постійної потужності $\mathrm{N}=$ const в діапазоні 5 40 кВт.

На основі аналізу ВАХ визначена область стійкої роботи ЕТПКШ, яка виключає ймовірність короткого замикання і різкого падіння потужності. Для частинок заданого розміру кожної продуктивності відповідає своя гранична температура, яка може бути досягнута в процесі експлуатації. Ця температура знаходиться в точці дотику лінії $\mathrm{U}(\mathrm{I}, \mathrm{G}=\mathrm{const})$ до кривої 
$\mathrm{U}(\mathrm{I}, \mathrm{t}=$ const $)$.

За результатами аналізу ВАХ-к печі розроблені режими розігріву, зміни температури і продуктивності, а також підтримки заданого продуктивності і температури.

\section{Бібліографічний список}

1. Jewell S., Kimball S. M. Mineral commodity summaries 2017. Reston, US : U.S. Geological Survey, 2017. 150 p.

2. Siow K.S. Graphite Exfoliation to Commercialize Graphene Technology. Sains Malaysiana. 2017. Vol. 46, No. 7. P. 1047-1059. DOI: 10.17576/jsm-2017-4607-06

3. Ukraine's Graphite Perspectives In Li-Ion Battery Supply Chains / S. Fedorov, et. al. Information technology in metallurgy and machine building : Materials of Scientific and Technical International Conference, 26-28 ${ }^{\text {th }}$ March, 2019.

4. Kieush L., Fedorov S., Koveria A., Sybir A. The biomass utilization to obtain high-purity carbonaceous materials. Selected aspects of providing the chemmotological reliability of the engineering : monograph / Ed. S. Boichenko, et. al. Kyiv-Paris, National Aviation University, 2019. P. 20-31. DOI: doi.org/10.18372/38222.

5. Fedorov S.S., Gubinskii M.V., Foris S.N. Mathematical Simulation of the Structural Properties of Packed and Fluidized Beds. Journal of Engineering Physics and Thermophysics. 2016. Vol. 8, No. 3. P. 627-635. DOI: 10.1007/s10891-016-1420$\mathrm{x}$.

6. Fedorov S. S., Gubinsky M. V., Foris S. N. Research of the influence of the sub electrode section on the work of electro-thermal fluidized bed furnaces. Metallurgical and Mining Industry. 2015. No.9. P. 1202-1205.

7. Локальная проводимость кипящего слоя, состоящего из электропроводных частиц / Малиновский А. И. и др. Инженернофизический журнал. 2012. Т. 85, № 2. С. 239245.

8. Jones A. L. Electrical resistivity of carbon granules in a fluidized bed. Ph.D. thesis / Iowa State University, Ames, US, 1966. 193 p. URL: https://lib.dr.iastate.edu/rtd/3106.

9. Gupta C.K., Sathiyamoorthy D. Fluid bed technology in materials processing. Boca Raton, Fla.: CRC Press, 1999. 528 p.

\section{References}

1. Jewell, S., \& Kimball S. M. (2017). Mineral commodity summaries 2017. Reston, US: U.S. Geological Survey.

2. Siow, K. S. (2017). Graphite Exfoliation to
Commercialize Graphene Technology, Sains Malaysiana, 46(7), 1047-1059. DOI: 10.17576/jsm2017-4607-06.

3. Fedorov, S., Hubinskyi, S., Sybir, A., Hubinskyi, S., \& Foris, S. (2019) Ukraine's Graphite Perspectives In Li-Ion Battery Supply Chains, Materials of Scientific and Technical International Conference INFORMATION TECHNOLOGY IN METALLURGY AND MACHINE BUILDING 26$28^{\text {th }}$ March, 2019.

4. Kieush, L., Fedorov, S., Koveria, A., \& Sybir, A. (2019). The biomass utilization to obtain high-purity carbonaceous materials. National Aviation University. doi: doi.org/10.18372/38222.

5. Fedorov, S. S., Gubinskii, M. V., \& Foris, S. N. (2016). Mathematical Simulation of the Structural Properties of Packed and Fluidized Beds. Journal of Engineering Physics and Thermophysics, 89(3), 627-635. doi: 10.1007/s10891-016-1420-x.

6. Fedorov, S. S., Gubinsky, M. V., \& Foris, S. N. (2015). Research of the influence of the sub electrode section on the work of electro-thermal fluidized bed furnaces. Metallurgical and Mining Industry, (9), 1208-1211.

7. Malinovskyi, A. I., Rabinovich, O. S., Borodulya, V. A., Grebenkov, A. Zh., \& Sidorovich, A. M. (2012). Lokalnaya provodimost kipaschego sloya, sostoyaschego iz electroprovodnikh chastits. Journal of Engineering Physics and Thermophysics, 85(2), 239-245.

8. Jones, A. L. (1966). Electrical resistivity of carbon granules in a fluidized bed (Ph.D. thesis, Iowa State University, Ames, US). Retrieved from https://lib.dr.iastate.edu/rtd/3106.

9. Gupta, C. K., \& Sathiyamoorthy, D. (1999). Fluid bed technology in materials processing. Boca Raton: CRC Press.

Purpose: The aim of the study was the determination of the operating modes for the laborato$r y$ electro-thermal fluidized bed furnace of 10 $\mathrm{kg} / \mathrm{h}$ productivity to obtain new scientific and practical data on current-voltage curves relevant for such units and further selection of respective electrical power sources.

Methodology: The study of the furnace operation was conducted by simulation of its thermal balance and electric resistance at relevant modes. For calculation of the current-voltage curves there were used equations for electric power, resistivity of fluidized bed as well as dependences for total, useful and no-load power at various operating temperatures and productivity.

Findings: It has been obtained the currentvoltage curves of the fluidized bed furnace of 
$10 \mathrm{~kg} / \mathrm{h}$ productivity which are presented by curves of the electro-thermal fluidized bed for defined operating temperatures $0-2700{ }^{\circ} \mathrm{C}$; curves of the electro-thermal fluidized bed for defined furnace productivities $G=0-10 \mathrm{~kg} / \mathrm{h}$; curves for current density on the lining and electrodes surfaces and average current density by furnace radius $i(I)$; curves for constant power in range $5-40 \mathrm{~kW}$. On the basis of analysis, the area of the furnace steady operation mode has been defined that excludes the possibility of a short circuit. It has been also developed the modes of heating up, temperature and productivity transition as well as algorithms to sustain given productivity and operating temperature.

Originality: For the first time, it has been scientifically justified the selection of operating modes providing control of electric power for the electro-thermal fluidized bed furnace on the basis of its current-voltage curves, and defined area of the furnace steady operation.

Practical value: As a result of the study, the technical requirements for the manufacturing of the electric power source for the laboratory electro-thermal-fluidized bed furnace of $10 \mathrm{~kg} / \mathrm{h}$ productivity at Material Research Center, Ltd (Kyiv, Ukraine) were developed.

Keywords: electro-thermal furnace, fluidized bed, graphite purification, operating modes.

Цель: Целью исследований режимов лабораторной электротермической печи кипящего слоя производительностью 10 кг/ч было получение новых научно-практических данных о вольтамперных характеристиках подобных агрегатов для дальнейтего выбора соответствующих электрических источников питания.

Методика: Исследование работы печи выполнялось путем математического моделирования ее теплового баланса и электрического сопротивления при соответствующих режимах. Для построения вольтамперных характеристик были использованы зависимости электрической мощности и удельного электрического сопротивления слоя, а также уравнения общей, полезной и мощности холостого хода при разных значениях рабочей температуры и производительности.

Результаты: Построены и исследованы вольтамперные характеристики печи кипящего слоя производительностью $10 \mathrm{\kappa} / ч$, которые включают характеристики электротермического кипящего слоя для заданных значений температуры в диапазоне $0-2700{ }^{\circ} \mathrm{C}$; характеристики электротермического кипящего слоя для производительности печи $G=0-10 \kappa 2 / 4 ;$ кривые плотности тока на поверхности центрального электрода, на поверхности футеровки и средней по радиусу печи i(I); кривые постоянной мощности $N=$ const в диапазоне $5-40 \kappa \mathrm{Bm}$. На основе анализа результатов определена область устойчивой работы электротермической печи, которая исключает вероятность короткого замыкания. Разработаны режимы разогрева, изменения температуры и производительности, а также алгоритмы поддержания заданных производительности и температуры.

Научная новизна: Bпервые научно обоснован выбор режимов управления электрической мощностью электротермической печи кипящего слоя на основе ее вольтамперных характеристик и определена область устойчивой работы печи.

Практическая ценность: По результатам исследований разработано техническое задание на изготовление электрического источника питания лабораторной электротермической печи кипящего слоя производительностью 10 кг/ч для условий ООО «Центр материаловедения» (Киев, Украина).

Ключевые слова: электротермическая печь, кипящий слой, рафинирование графита, режимы работы.

Рукопис надійшов 01.08.2019 